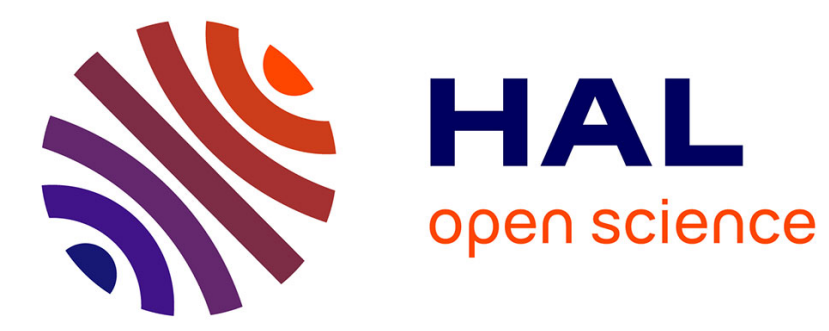

\title{
Advances in magnetic recording materials
}

\author{
A.A. van Der Giessen
}

\section{To cite this version:}

A.A. van Der Giessen. Advances in magnetic recording materials. Revue de Physique Appliquée, 1974, 9 (5), pp.869-876. 10.1051/rphysap:0197400905086900 . jpa-00243852

\section{HAL Id: jpa-00243852 https://hal.science/jpa-00243852}

Submitted on 1 Jan 1974

HAL is a multi-disciplinary open access archive for the deposit and dissemination of scientific research documents, whether they are published or not. The documents may come from teaching and research institutions in France or abroad, or from public or private research centers.
L'archive ouverte pluridisciplinaire HAL, est destinée au dépôt et à la diffusion de documents scientifiques de niveau recherche, publiés ou non, émanant des établissements d'enseignement et de recherche français ou étrangers, des laboratoires publics ou privés. 


\title{
ADVANCES IN MAGNETIC RECORDING MATERIALS
}

\author{
A. A. VAN DER GIESSEN
}

Philips Research Laboratories Eindhoven, The Netherlands

\begin{abstract}
Résumé. - L'enregistrement magnétique est principalement effectué sur des couches minces constituées de particules magnétiques disposées dans un liant organique.

Ces particules sont des monodomaines, soit de $\gamma-\mathrm{Fe}_{2} \mathrm{O}_{3}$, soit de $\mathrm{CrO}_{2}$ présentant une anisotropie magnétique provoquée par leur forme aciculaire.

Les performances des couches à base de $\gamma-\mathrm{Fe}_{2} \mathrm{O}_{3}$ ont été considérablement améliorées ces cinq dernières années. Le résultat a pu être obtenu grâce à un perfectionnement de la morphologie des particules. Les efforts déployés pour atteindre avec les oxydes de fer les mêmes performances à l'enregistrement qu'avec $\mathrm{CrO}_{2}$, et ce par augmentation de leur anisotropie magnétocristalline, par dopage à l'aide de cobalt, ont échoué jusqu'à présent du fait de leur stabilité physique insuffisante.

La morphologie de $\mathrm{CrO}_{2}$ est bonne à l'heure actuelle, en conséquence il est peu probable qu'une meilleure mise en forme des oxydes permette d'atteindre des améliorations de performances.

Un progrés considérable - $6 \mathrm{~dB}$ comparé au $\mathrm{CrO}_{2}$ - est pourtant possible, en utilisant des particules bien formées de fer métallique, grâce à leur saturation magnétique plus élevée.
\end{abstract}

Abstract. - Magnetic recording is mainly carried out on thin layers that consist of a dispersion of magnetic particles in an organic binder system.

These particles are single domains of either $\gamma-\mathrm{Fe}_{2} \mathrm{O}_{3}$ or $\mathrm{CrO}_{2}$, the magnetic anisotropy of which is due to their acicular shape.

The recording performance of $\gamma-\mathrm{Fe}_{2} \mathrm{O}_{3}$ coatings have been enhanced considerably in the past five years by improving the particle morphology. Attempts to make the recording quality of iron oxides equal to that of $\mathrm{CrO}_{2}$ by increasing their magnetocrystalline anisotropy by Co-doping failed because of the resultant insufficient physical stability.

Taking into account the good morphology of the present $\mathrm{CrO}_{2}$ a further significant increase of recording performance by the architecturing of oxidic materials is not to be expected.

Considerable progress, $\sim 6 \mathrm{~dB}$ with respect to $\mathrm{CrO}_{2}$, is possible, however, by using well-shaped metallic iron or iron-alloy particles, owing to their much higher saturation magnetization.

1. Introduction. - In the recent literature there are excellent surveys concerning the knowledge acquired and the progress which has been achieved in the past decade in the domain of materials for sine wave as well as for digital recording [1-2-3-4].

There would be little sense in compiling another complete review. It seems more significant to emphasize the origins of the improvements attained in the past few years in the field of the materials for magnetic recording. On the basis of the knowledge of these origins, it is perhaps possible to indicate the trends for the near future, taking account of the physical constraints of the recording system.

A complete theoretical description of the recordingreplay process is required to indicate the theoretical limits of the signal and noise imposed by the available magnetic materials and to predict the requirements these materials should meet in order that these limits can be attained.

There is indeed an adequate theory for the replay process ; for the write process, however, such a theory is lacking.

Much knowledge concerning magnetic recording is compiled in the well-known book of Mee [5], dating from 1964. A more recent description of the state of the art is given in [6]. After 1964 various investigators have deepened the insights into the theory of the sine-wave writing process e. g. Tjaden with the aid of a largescale model [7] and with the aid of computer simulation [8], however, without arriving at a complete description of the sine-wave write-process. A similar situation exists for digital recording on particulate media [9] while for recording on continuous layers several elucidating papers appeared [9-10]. A discussion about the sources that contribute to the noise has been given lately by Daniel [11].

In spite of the incompleteless of the theoretical knowledge, it is possible, on the grounds of the existing theoretical insight and experimental evidence to formulate the demands materials for magnetic recording should meet. These delineate the scope of further research.

2. Material parameters relevant for high-density recording. - In digital registration in order to obtain a sufficient signal output, it is required that the necessarily thin recording layer has a high remanence and as high a coercivity as possible. The upper level of the 
coercivity is determined by the saturation of the writehead material.

These considerations suggest that continuous magnetically anisotropic metallic films could be ideal recording surfaces, especially for digital applications. In practice the highest recording densities can be achieved with Cobalt-Phosphorus layers and with a thickness far below $1 \mu \mathrm{m}$. Despite considerable efforts these have not yet found a wide-spread application. No conclusive arguments can be given for it [2]. A possible explanation could be the insufficient resistance against mechanical and chemical attack leading to drop-outs.

For audio and video registration, likewise a recording surface with a high remanence and coercivity are preferable to obtain a high signal strength.

For audio the layer thickness is matched to the requirements of the recording of long-wave-length signals. In practice it varies between 3 and $10 \mu \mathrm{m}$.

It must be emphasized, however, that for short wavelengths the remanent magnetization induced by the write field is only a small fraction of the remanent flux density of the recording medium (Fig. 1) and as a consequence the search for a better material not necessarily implies exclusively the use of materials with a high magnetic saturation. This low efficiency is caused by a combination of factors, $i$. e. the spread in interaction fields of the magnetic domains, the spread in the domain switching fields and the impact of the demagnetizing fields during the recording $\left({ }^{1}\right)$.

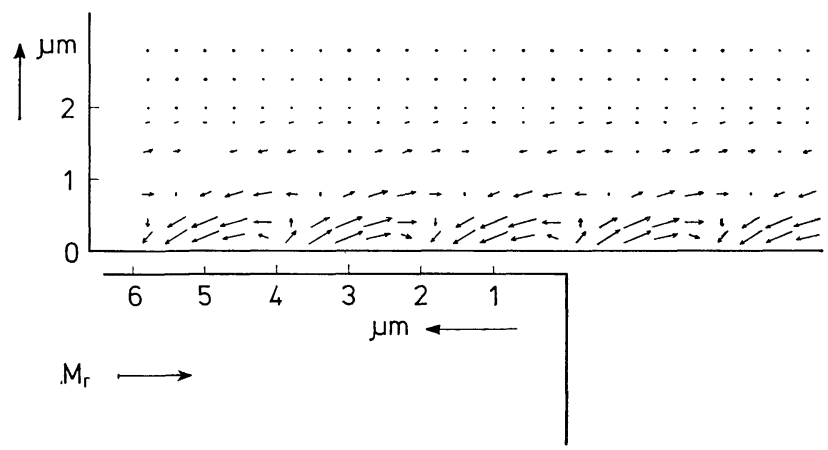

FIG. 1. - Magnetization distribution of a signal with a wavelength of $4 \mu \mathrm{m}$ written on a $\gamma-\mathrm{Fe}_{2} \mathrm{O}_{3}$ tape with a layer thickness of $10 \mu \mathrm{m}$. Gaplength $4 \mu \mathrm{m}$. Surface to head distance $0.3 \mu \mathrm{m}$. Bias and signal current are optımized for maximum output. The picture results from experiments with a large scale model by Tjaden [7]

The easy directions of magnetization of the domains have to be oriented parallel to the head surface. A high degree of orientation diminishes the influence of the vertical component of the writing-field. This vertical component has a less steep gradient than the horizontal one and thus gives rise to a smaller resolution [12].

The magnetization must be temperature independent. In this respect the magnetic hardness should preferably

(1) TJaden, D. L. A., Private Communication. be due to shape anisotropy instead of crystalline anisotropy, the latter being strongly temperature dependent for the materials of interest.

Magnetic recording is predominantly carried out on media consisting of either a rigid or a flexible substrate covered by a layer that consists of a dispersion of magnetic particles in an organic binder. It will be clear that, in order that in such a system the particles have large and uniform switching fields owing to their shape, they should preferably be needle shaped and contain only one magnetic domain. This limits the upper particle size for the available materials to about $1 \mu \mathrm{m}$ and implies a length to diameter ratio larger than 5 . It follows from theory that the signal to noise ratio is proportional to the square root of the number of domains and as a consequence the particles must be as small as possible at a given packing density. There is a lower size limit where superparamagnetic behaviour becomes manifest; for the available materials about $0.02 \mu \mathrm{m}$

An additional condition that the particles have to fulfil is that they can be dispersed in the binder in such a way that smooth surfaces are obtained, thus avoiding a decrease in short wave-length output or a large contribution to the modulation noise due to surface roughness.

Taking the arguments above into account, the best choice for a magnetic material are $\mathrm{Fe}$ or $\mathrm{Fe}-\mathrm{Co}$ alloys which have the highest attainable saturation. Attempts to prepare powders from these materials, suitable to give layers with a superior recording quality, did not succeed until recently.

On a technical scale exclusively oxides, i. e. mainly $\gamma-\mathrm{Fe}_{2} \mathrm{O}_{3}$ and in minor quantities also $\mathrm{CrO}_{2}$ are applied. It has been tried to improve the recording performance of the oxides by improving the particle morphology and by increasing their magnetocrystalline anisotropy. How this has been done and which results this has yielded will be discussed below. The author will restrict himself to examples from sine wave recording. The material problems for digital recording are in principle the same.

3. Magnetic materials for recording surfaces. $3.1 \gamma-\mathrm{Fe}_{2} \mathrm{O}_{3}$. - 3.1.1 Structure and magnetic behaviour. - Until a few years ago, exclusively $\gamma-\mathrm{Fe}_{2} \mathrm{O}_{3}$ was used for digital as well as for sine wave recording.

This material has a cubic symmetry with a spinel lattice with $a_{0}=8.34 \AA$ and with an X-ray density of $4.9 \times 10^{3} \mathrm{~kg} / \mathrm{m}^{3}$. It has some crystalline anisotropy, $K_{1}=-4.64 \times 10^{3} \mathrm{~J} / \mathrm{m}^{3}$ [13] and [111] as the preferred direction. This small anisotropy means that the desired magnetic hardness must be derived from shape anisotropy ; as a consequence it has been tried to give the particles an acicular shape.

The available $\gamma-\mathrm{Fe}_{2} \mathrm{O}_{3}$ powders consist of needles the majority of which has [110] as the long axis [14-15].

The mechanism of magnetization reversal is not known. If the magnetic vector rotates coherently, then 
the coercivity of a random powder should be in the order of $10^{5} \mathrm{~A} / \mathrm{m}$. In reality this is lower by a factor of 3 to 5 . This means that flux reversal occurs by an incoherent mechanism [16].

3.1.2 Preparation. - Due to the cubic symmetry a direct formation of elongated $\gamma-\mathrm{Fe}_{2} \mathrm{O}_{3}$ particles in a crystal growth process is not possible. The desired acicular shape, with a length to diameter ratio above five, must be attained in a roundabout way. This is done, as initially proposed by Camras [17], by a pseudomorphosis in which first acicular $\mathrm{FeOOH}$ is prepared, reduced to $\mathrm{Fe}_{3} \mathrm{O}_{4}$ and then converted to $\gamma-\mathrm{Fe}_{2} \mathrm{O}_{3}$ according to :

$\mathrm{FeOOH} \stackrel{200^{\circ} \mathrm{C}}{\longrightarrow} \alpha-\mathrm{Fe}_{2} \mathrm{O}_{3} \stackrel{\mathrm{H}_{2}, 400^{\circ} \mathrm{C}}{\longrightarrow} \mathrm{Fe}_{3} \mathrm{O}_{4} \stackrel{\mathrm{O}_{2}, 250^{\circ} \mathrm{C}}{\longrightarrow} \gamma-\mathrm{Fe}_{2} \mathrm{O}_{3}$.

The morphology of the $\gamma$-oxide thus depends considerably on that of the starting $\mathrm{FeOOH}$. This may be either $\gamma$ or $\alpha-\mathrm{FeOOH}$. One can only guess at the way in which the $\mathrm{FeOOH}$ is prepared from which the commercially available $\gamma-\mathrm{Fe}_{2} \mathrm{O}_{3}$ is obtained. The $\alpha-\mathrm{FeOOH}$ (goethite) is probably prepared according to a procedure invented by Penniman and Zoph [18] where iron scrap, in a weakly acid solution, is oxidized by bubbling air through it. The $\gamma$-FeOOH (lepidocrocite) can be prepared by blowing air in an aqueous solution of a ferrous salt which is kept at a $\mathrm{pH}$ of about 3 [19].

The pseudomorphic conversion of the $\mathrm{FeOOH}$ yields $\gamma-\mathrm{Fe}_{2} \mathrm{O}_{3}$ particles with a morphology that only more or less resembles that of the starting material. During the conversion the formation of agglomerates occurs. The resultant agglomerates in the recording surface increase the noise level and decrease the signal strength due to a larger spread in the switching fields, a diminished orientability and in some cases a worsened surface roughness. The formation of agglomerates is stimulated as the conversion temperature is higher. On the other hand, already during the dehydration step holes and fissures are formed, which may partly disappear at higher temperatures [20]. The influence which these defects might have on the magnetic anisotropy of the $\gamma-\mathrm{Fe}_{2} \mathrm{O}_{3}$ is not known. In any case it is certain that, due to a lower material density of the recording layer a proportionally lower remanence results.

It can be concluded that the art of the preparation of $\gamma-\mathrm{Fe}_{2} \mathrm{O}_{3}$ comprises to a large extent the control of the reaction parameters that govern the conversion of $\mathrm{FeOOH}$ into $\gamma-\mathrm{Fe}_{2} \mathrm{O}_{3}$.

In figures 2 and 3 examples are given of an $\alpha-\mathrm{FeOOH}$ powder and the $\gamma-\mathrm{Fe}_{2} \mathrm{O}_{3}$ prepared from it. Apparently the degree of aggregation is reasonable. A close inspection shows that the magnetic material contains cavities.

3.1.3 Progress. - The improvements in recording performance which have been achieved in the past years are largely attributable to a better shaping of the starting $\mathrm{FeOOH}$. Recently investigators from Japanese as well as American [21-22] industries introduced better powders with a particle length below $0.5 \mu \mathrm{m}$ and a length to diameter ratio up to 10 . With these powders

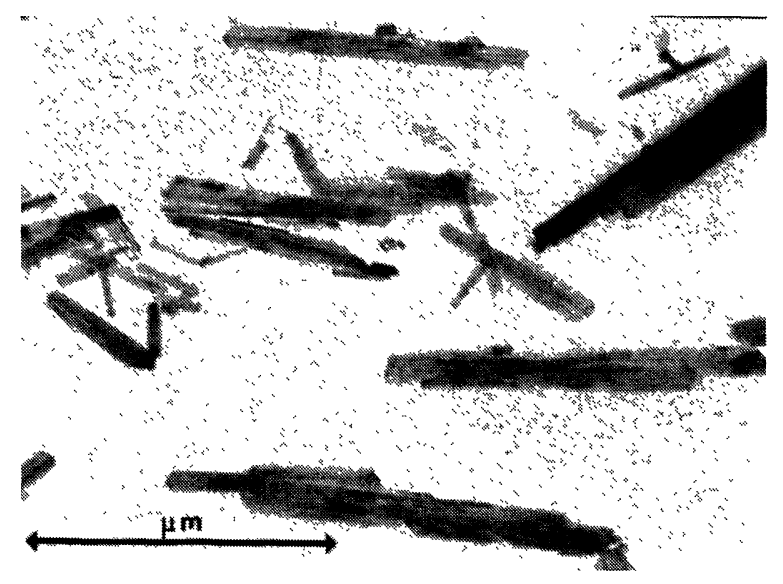

FIG. 2. - Electronmicrograph of a $\alpha-\mathrm{FeOOH}$ powder.

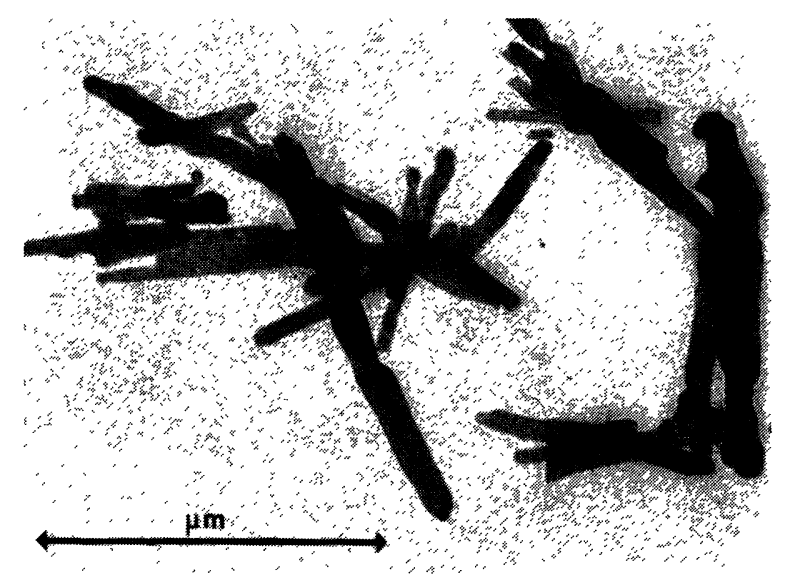

FIG. 3. - Electronmicrograph of a modern $\gamma-\mathrm{Fe}_{2} \mathrm{O}_{3}$ powder prepared from the $\alpha-\mathrm{FeOOH}$ depicted in figure 2 .

recording surfaces can be obtained with a high degree of orientation and a good squareness. The coercivity can be as high as $38 \times 10^{3} \mathrm{~A} / \mathrm{m}$; usually it is between 25 and $30 \times 10^{3} \mathrm{~A} / \mathrm{m}$, tables I and II.

\section{TABLE I}

Magnetic properties of $\gamma-\mathrm{Fe}_{2} \mathrm{O}_{3}, \mathrm{CrO}_{2}$ and metal powders for magnetic recording purposes

\begin{tabular}{|l|c|c|c|}
\hline POWDER & $\begin{array}{c}H_{C} \times 10^{-3} \\
(\mathrm{~A} / \mathrm{m})\end{array}$ & $\begin{array}{c}\sigma_{S} \times 10^{6} \\
(\mathrm{Wbm} / \mathrm{kg})\end{array}$ & $\sigma_{R} / \sigma_{S}$ \\
\hline$\gamma^{-} \mathrm{Fe}_{2} \mathrm{O}_{3}$ & 28 & 90 & 0.45 \\
$\mathrm{CrO}_{2}$ & 38 & 100 & 0.40 \\
$\mathrm{Fe}$-metal & 81 & 190 & 0.46 \\
\hline
\end{tabular}

The improved morphology may be illustrated by comparing a modern $\gamma-\mathrm{Fe}_{2} \mathrm{O}_{3}$, figure 3 , with that of a powder that, about five years ago was considered to be an advanced one, figure 4 . Perhaps even more convin- 
TABLE II

Characteristic data of oxide tapes $\gamma-\mathrm{Fe}_{2} \mathrm{O}_{3}\left(\right.$ ref.), $\mathrm{CrO}_{2}$ and experimental $\mathrm{Fe}-$ metal tape

\begin{tabular}{|l|c|c|c|c|c|}
\hline TAPE & $\begin{array}{c}\text { coating } \\
\text { thickness } \\
(\mu \mathrm{m})\end{array}$ & $\begin{array}{c}\text { vol packing } \\
\%\end{array}$ & $\begin{array}{c}\mathrm{H}_{\mathrm{C}} \times 10^{-3} \\
(\mathrm{~A} / \mathrm{m})\end{array}$ & $\begin{array}{c}\mathrm{Bs} \\
\left(\mathrm{Wb} / \mathrm{m}^{2}\right)\end{array}$ & $\mathrm{Br} / \mathrm{Bs}$ \\
\hline$\gamma-\mathrm{Fe}_{2} \mathrm{O}_{3}$ (ref) & 46 & 33 & 29 & 015 & 079 \\
$\mathrm{CrO}_{2}$ & 40 & 38 & 39 & 018 & 073 \\
$\mathrm{Fe}$-metal & 31 & 28 & 77 & 037 & 072 \\
\hline
\end{tabular}

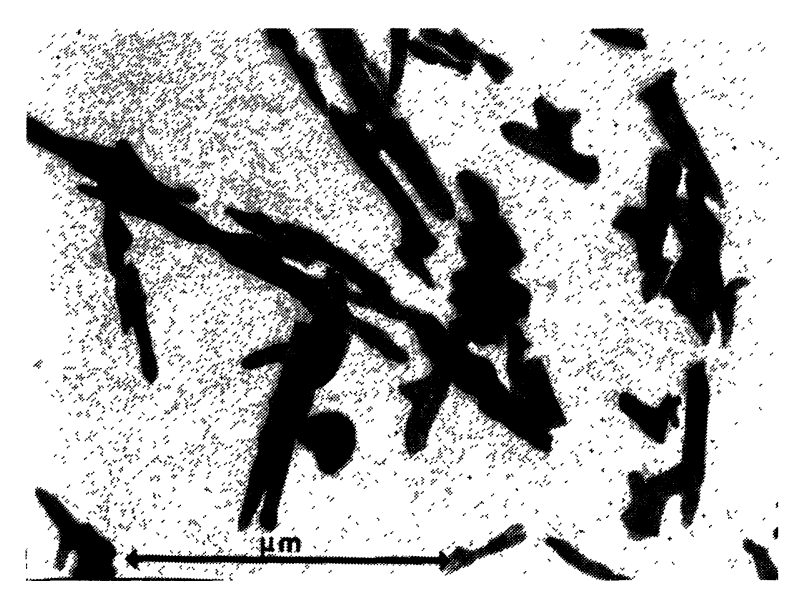

FIG. 4. - High-quality 1969 commercial $\gamma-\mathrm{Fe}_{2} \mathrm{O}_{3}$ powder.

\section{TABLE III}

Record. performance of top quality commercial oxide tapes and of an experimentalmetal tape $(*)$. Recordhead : $\mu$ metal, gap length $2.5 \mu \mathrm{m}$. Repro. head:ferroxcube, gap length $0.7 \mu \mathrm{m}$; track width $2 \mathrm{~mm}$. Tape speed: $4.75 \mathrm{~cm} / \mathrm{s}$.

\begin{tabular}{|l|c|c|c|c|c|}
\hline & $\begin{array}{c}\gamma-\mathrm{Fe}_{2} \mathrm{O}_{3} \\
(1969)\end{array}$ & $\begin{array}{c}\gamma-\mathrm{Fe}_{2} \mathrm{O}_{3} \\
(1974)\end{array}$ & $\begin{array}{c}\gamma-\mathrm{Fe}_{2} \mathrm{O}_{3} \\
(\mathrm{ref})\end{array}$ & $\mathrm{CrO}_{2}$ & $\mathrm{Fe}$-metal \\
\hline $\begin{array}{c}\text { Playback equalization } \\
\text { ( } \mu \text { sec) }\end{array}$ & 120 & 120 & 120 & 70 & 70 \\
Bias noise (weighted) & -515 & -52 & -525 & -54 & -54 \\
MOL 333 Hz (5\% thd) & -2 & +1.5 & +0.5 & 0 & +45 \\
MOL $8 \mathrm{kHz}(1.5 \mathrm{~dB}$ compr) & -12 & -8 & -9 & -8 & -2 \\
SAT 10 kHz & - & - & -13 & -10 & -4 \\
SAT $12.5 \mathrm{kHz}$ & - & - & -18 & -14 & -8 \\
\hline
\end{tabular}

cingly the progress can be demonstrated with table III, where the recording properties of 1969 and 1974 top quality audio cassette tapes are given together with the present reference, BASF P. E. S. 12 D. I. N. standard.

3.2 Co-DOPED $\gamma-\mathrm{Fe}_{2} \mathrm{O}_{3} .-3.2 .1$ Structure and magnetic behaviour. - Another approach to increase the coercivity is to introduce crystalline anisotropy by building Co(II) ions in the spinel lattice. This does not change the crystal structure. The anisotropy constant,

(*) DATA : dB with reference to a level of $250 \mathrm{pWb} / \mathrm{mm}$. however, changes from the negative value of $-4.64 \times 10^{3} \mathrm{~J} / \mathrm{m}^{3}$ characteristic of $\gamma-\mathrm{Fe}_{2} \mathrm{O}_{3}$ to a positive value that depends upon the quantity of $\mathrm{Co}$ (II) ions in the lattice. The anisotropy is already large at small $\mathrm{Co}(\mathrm{II})$ concentrations : at $4 \% \mathrm{Co}, K_{1}$ amounts to $10^{5} \mathrm{~J} / \mathrm{m}^{3}$ [23-16]. The easy axis thus shifts from the [111] to the [100] direction. Hence the homogeneity of the distribution of the Co in the lattice is important for the magnetic behaviour. This requirement for homogeneity imposes severe demands on the preparation methods.

The coercivities of Co-doped materials, being due to crystal anisotropy, exhibit a strong temperature dependency. Moreover the material shows instabilities as a result of magnetostrictive effects. An additional source of instability is probably the diffusion of the Co(II) ion over the cation vacancies of the spinel lattice toward ordered positions which are determined by the direction of the magnetization.

Such effects result in a strong temperature/time dependency of the recording replay properties.

3.2.2 Preparation. - The preparation of Co-doped iron oxides is carried out according to the patent literature, by soaking an iron oxide with a solution of a $\mathrm{Co}$ (II) salt before the subsequent conversion to $\gamma-\mathrm{Fe}_{2} \mathrm{O}_{3}[24,25]$ or by carrying out the oxidation of $\mathrm{Fe}$ (II) to $\mathrm{FeOOH}$ in the presence of $\mathrm{Co}(\mathrm{II})$ ions [26, 27, $28,29]$.

3.2.3 Progress. - The idea to increase the anisotropy of recording oxides with Co is already more than 20 years old [30]. Due to the strong temperature/time instability of the - at that time spherical - materials these had only a temporary commercial success.

In the past years this theme has been reconsidered, now by doping acicular oxides in order to fall back on shape anisotropy at elevated temperature. The American 3M company introduced the so-called HighEnergy tape. In Japan a similar tape is fabricated by T. D. K. Such tapes have a coercivity of $40 \times 10^{3} \mathrm{~A} / \mathrm{m}$ which make them compatible with present $\mathrm{CrO}_{2}$ tapes which are increasingly used for audio and more particularly for video recording. Their signal strength is indeed markedly higher than for $\gamma-\mathrm{Fe}_{2} \mathrm{O}_{3}$ tape [31]. However the instabilities make it not probable that recording surfaces on the basis of Co doped oxides will find a wide-spread application. Yet a tremendous effort is still going on as is apparent from the patent literature [32].

3.3 $\mathrm{CrO}_{2}$. - 3.3.1 Structure andmagnetic properties. - $\mathrm{CrO}_{2}$ has a tetragonal crystal structure with $a_{0}=4.41 \AA$ and $c_{0}=2.91 \AA$; the X-ray density is $4.9 \times 10^{3} \mathrm{~kg} / \mathrm{m}^{3}$. The magnetic saturation is higher than that of $\gamma-\mathrm{Fe}_{2} \mathrm{O}_{3}$, cf. Table I.

The $\mathrm{CrO}_{2}$ used for recording purposes consists of elongated, submicroscopic, particles (Fig. 5) with the [001] direction parallel to the long axis. The crystal anisotropy is relatively large,

$$
K=+2.5 \times 10^{4} \mathrm{~J} / \mathrm{m}^{3}[33,34] .
$$




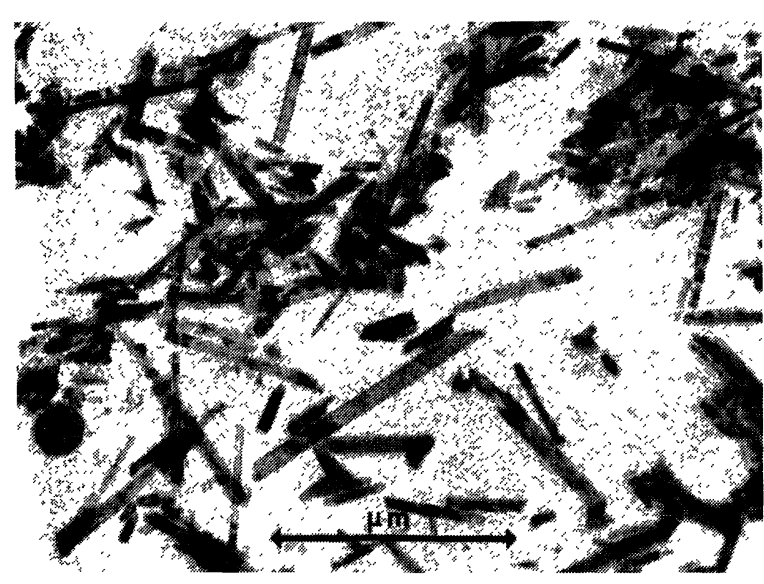

FIG. 5. $-\mathrm{CrO}_{2}$ powder used for magnetic recording purposes.

The observed coercivity, $H_{\mathrm{c}}$, is $4 \times 10^{4} \mathrm{~A} / \mathrm{m}$. Experiments indicate that the shape anisotropy is dominant.

According to Rodbell [34] the preferred direction is [001] and thus coincides with the long particle axis. This is in contrast to conclusions from earlier work from which it was thought that the easy axis made an angle of 30 or $40^{\circ}$ with the needle axis. Switching of the magnetization occurs notwithstanding the good crystallinity, by an incoherent mechanism [35].

3.3.2 Preparation. $-\mathrm{CrO}_{2}$ is made on a technical scale by the decomposition of $\mathrm{CrO}_{3}$ under hydrothermal conditions, schematically represented by [36] :

$$
\mathrm{CrO}_{3} \rightleftharpoons \mathrm{CrO}_{2}+\mathrm{O}_{2}
$$

$\mathrm{CrO}_{2}$ is metastable at room temperature and atmospheric pressure [37]. At $300^{\circ} \mathrm{C}$ the equilibrium pressure equals $10 \mathrm{~kb}$. For a good reaction kinetics and a good morphology of the end product a controlled nucleation is essential. In the patent literature numerous proposals are to be found for appropriate dopes. An excellent dope is $\mathrm{Sb}_{2} \mathrm{O}_{3}$, with the aid of which the reaction can proceed at $300{ }^{\circ} \mathrm{C}$ and at 50 at., while needles are obtained with a good acicularity and, corresponding high coercivity.

An alternative method has been put forward lately ; instead of $\mathrm{CrO}_{3}$ a mixture of metallic $\mathrm{Cr}$ and $\mathrm{CrO}_{3}$ is used [38].

The pressure procedure is expensive and it is logical that much work has been done to find methods that yield $\mathrm{CrO}_{2}$ at one atmosphere. This has been tried by heating a mixture of $\mathrm{Cr}(\mathrm{OH})_{3}$ and $\mathrm{CrO}_{3}$ [39], by heating $\mathrm{CrO}_{3}$ in an atmosphere of $\mathrm{NO}_{2}+\mathrm{O}_{2}$ [40] and by crystallization from a melt $[41,42]$.

As far as may be concluded from this patent literature these methods all lead to inferior products and probably the commercially available $\mathrm{CrO}_{2}$ is only made by the hydrothermal method.

3.3.3 Progress and prospects. - Although the ferromagnetic properties of $\mathrm{CrO}_{2}$ are known for long [43], it were in the fifties scientist of Du Pont who realized that the material has a great recording potential [44]. In the past two decades they have done a lot of work to arrive at useful preparation methods. This work has resulted in a number of publications, and patents the oldest dating from 1958 [45] and it culminated into a magnetic tape that especially in the short wave-length region has a high signal to noise ratio, see for instance [46]. Some relevant data are given in table II and III.

The reason of this high short wave-length output is not known with certainty; it must probably be ascribed to a good orientability as well as a high magnetic moment and coercivity.

The morphology of $\mathrm{CrO}_{2}$ has a high degree of perfection as a result of which the dispersability in the binder is also adequate. Any further improvements in the future are likely to be obtained by synthesing smaller particles with a narrower size distribution. It may be assumed, however, that $\mathrm{CrO}_{2}$ indicates the limits of recording possibilities on the basis of wellarchitectured oxides.

3.4 Fe-Co-Alloys. - 3.4.1 Some historical notes. - Of all materials metallic iron and alloys of iron and cobalt have the highest magnetic saturation values. Yet they have not found an application in magnetic recording. The principal reasons are :

- difficulties with the preparation of homogeneous powders with the desired morphology,

- chemical instability (pyrophoricity),

- bad dispersability leading to an inhomogeneous particle distribution in the binder and to rough surfaces,

- the required high coercivity which makes the system incompatible and which, moreover, can cause difficulties in writing and erasing.

Nevertheless research on these alloy systems has continued. The many investigations for a suitable preparation method that were done about a decade ago yielded poor results, after which the interest in them decreased. In the past five years, probably also stimulated by the success of $\mathrm{CrO}_{2}$, the work is resumed on a world-wide scale, and seemingly, with some success.

3.4.2 Structure and magnetic behaviour. - Below $960^{\circ} \mathrm{C}$ iron crystallizes in the cubic bcc structure with $a_{0}=2.866 \AA$ at room temperature. The magnetic saturation is $275 \times 10^{-6} \mathrm{Wbm} / \mathrm{kg}$, the density $7.9 \times 10^{3} \mathrm{~kg} / \mathrm{m}^{3}$, table $\mathrm{I}$. The crystal anisotropy $K_{1}=4.8 \times 10^{4} \mathrm{~J} / \mathrm{m}^{3}$ although being large compared with that of $\gamma$-oxides, is insufficiently high to attain the required coercivities. Hence also for this material the main factor contributing to the magnetic anisotropy must be the shape.

Luborsky et al. studied the magnetic reversal in what they called "almost perfect whiskers » with the long axis in the [100] direction. For whiskers with a diameter below $1000 \AA$ the mechanism is incoherent, probably curling [47]. In less perfect elongated $\mathrm{Fe}$ particles the reversal is believed to occur by a chain of spheres mechanism $[48,49]$. 
3.4.3 Preparation. - In the literature numerous methods are described for the preparation of elongated iron particles. These will not be discussed here except one, a method based on the decomposition of oxalates. In this way, $\mathrm{Fe}-\mathrm{Co}$ powders have been prepared in the past, which yielded tapes with a significantly higher output than the iron oxide tapes of that time [50]. Noise data, resistance against mechanical load and chemical attack were not given. It can only be guessed whether these aspects hampered the application of these tapes.

The search for materials on the base of $\mathrm{Fe}$ has been intensified again, as proved by the number of conference papers and patent applications now being produced. Apparently two lines are followed :

1) Reduction of a solution of a $\mathrm{Fe}$ (II) salt with the aid of $\mathrm{NaBH}_{4}$ and 2) pseudomorphic reduction of iron oxides with $\mathrm{H}_{2}$.

Reduction of $\mathrm{Fe}(\mathrm{II})$ salts solution with $\mathrm{NaBH}_{4}$. When aqueous solutions of $\mathrm{NaBH}_{4}$ and $\mathrm{FeSO}_{4}$ are mixed a precipitate of metallic iron is formed, containing some $\mathbf{B}$ and consisting of strings of more or less spherical beads. Under optimum conditions one $\mathrm{kg}$ of $\mathrm{NaBH}_{4}$ is reeded for one $\mathrm{kg}$ of iron, which implies that the process is expensive.

A search for the preparation of iron powders with this method was done in the early sixties [49]. This method still is the subject of research [51, 52, 53]. There are no reports known from the literature about the properties of recording layers containing these powders.

Pseudomorphic reduction of iron oxides. - It is obvious to prepare iron powders in just the same way as $\gamma-\mathrm{Fe}_{2} \mathrm{O}_{3}$ i. e. by a pseudomorphic reduction of FeOOH with $\mathrm{H}_{2}$. This has been tried already nearly twenty years ago [54]. The conversion is difficult to carry out and leads to sintered products. An important advance was the finding that with certain dopes the pseudomorphosis can be improved considerably [55, 56]. Also through adsorption of relatively large quantities of $\mathrm{Co}(\mathrm{OH})_{2}$, on the particle surface of the starting $\mathrm{FeOOH}$, powders are obtained having a reasonable morphology. With these powders tapes can be made with a short wave-length output which is twice as high as that of a $\mathrm{CrO}_{2}$ tape [57]. No data are given about the noise and the chemical stability.

4. Acicular iron particles the magnetic recording material of the future ? - The first detailed set of data concerning a recording medium based upon metallic particles was published in the proceedings of the 1973 Intermag conference, where the author reported the recording performance of experimental tapes obtained from powders that were prepared by the pseudomorphic conversion of acicular iron oxides [58]. Some relevant data will be presented here.

Tapes have been made with a metal powder of which an electronmicrograph is given in figure 6 and of which the magnetostatic properties are collected in

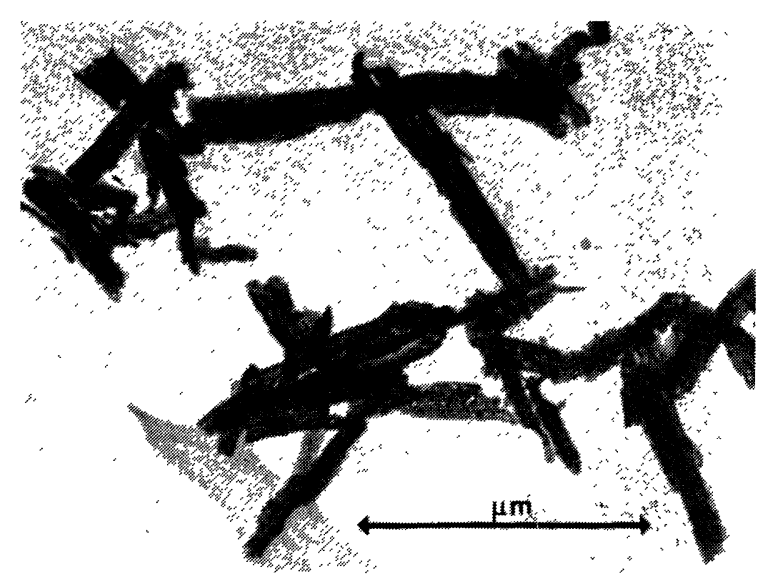

FIG. 6. - Iron powder used for the preparation of the tape, the data of which is given in the tables.

table I. The high coercivity, $H_{\mathrm{c}} \simeq 80 \times 10^{3} \mathrm{~A} / \mathrm{m}$ is mainly due to the particle shape.

The iron powder particles can be stabilized against air oxidation by coating them with an oxide layer. Even in humid air such powders oxidize only slowly, at elevated temperatures, figure 7 . Tapes made with such a stabilized powder have an excellent chemical stability. When kept in an atmosphere saturated with water vapour at $50^{\circ} \mathrm{C}$ for a period of nine months, only a small and, in comparison with $\mathrm{CrO}_{2}$, insignificant decrease in output level of a prerecorded signal with a wavelength of $24 \mu \mathrm{m}$ is observed. It should be remarked here that all recording materials, $\gamma-\mathrm{FeO}_{3}, \mathrm{CrO}_{2}$ and $\mathrm{Fe}$ are used under conditions in which they are thermodynamically unstable.

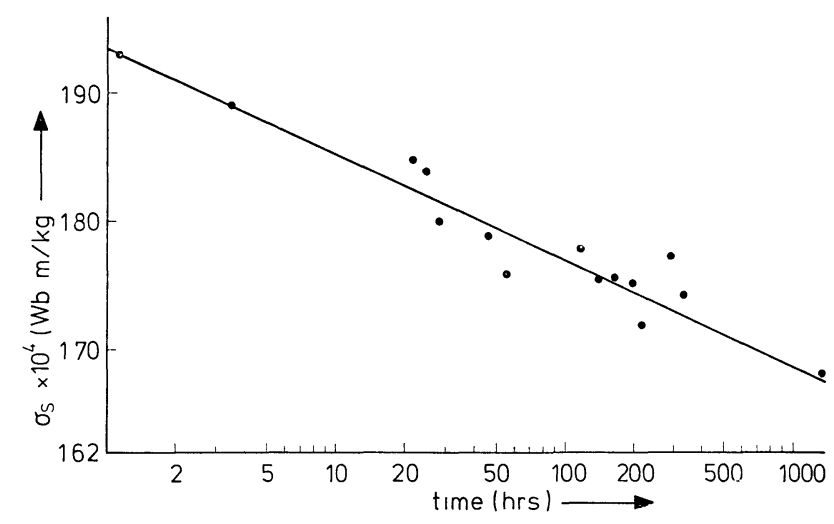

FIG. 7. - Oxidation velocity of an iron powder at $50^{\circ} \mathrm{C}$ in air of a relative humidity of $90 \%$.

Agglomerate formation, initially during the chemical conversion of $\alpha-\mathrm{FeOOH}$ into $\mathrm{Fe}$, as well as afterwards due to the strong magnetic attraction between the particles, might result into badly dispersable powders. Yet by carefully avoiding sintering, powders were obtained with which tapes could be made in which the particles are homogeneously distributed, figure 8 and 
which have a high orientation ratio $\left({ }^{2}\right)$. This together with the high magnetization of the metal powder leads to a high $\mathrm{Br}$ despite the relatively low packing density, table II.

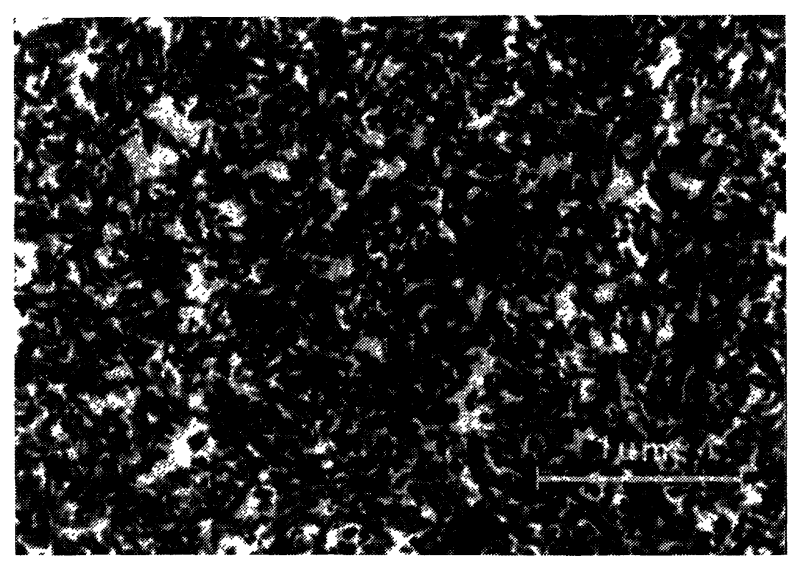

Fig. 8. - Electronmicrograph of a microtome slice of an iron tape.

The high output observed at long wavelengths is thus by no means surprising. Less predictable and of special interest is the high output at short wavelengths in combination with the low noise level. This means, that, for instance by application in audio-cassette recording,

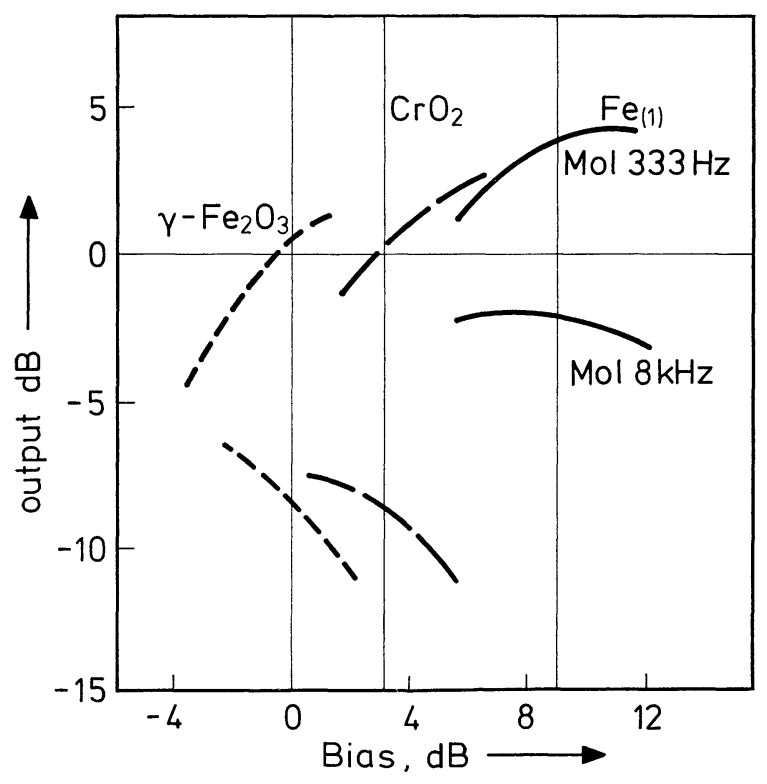

Fig. 9. - Output versus bias of $\gamma-\mathrm{Fe}_{2} \mathrm{O}_{3}, \mathrm{CrO}_{2}$ and $\mathrm{Fe}$-metal tapes. Output levels at $5 \%$ distortion $(333 \mathrm{~Hz})$ or $1.5 \mathrm{~dB}$ compression $(8 \mathrm{kHz})$. Other conditions as specified in table III.

(2) The orientation ratio is the ratio of the value of the remanent magnetization in the longitudinal direction to that in the cross direction. with respect to $\mathrm{CrO}_{2}$ a significantly ( $6 \mathrm{~dB}$ ) higher signal to noise ratio is achieved.

This higher output is probably also simply a result of the higher $B_{r}$ in combination with the proportionally higher $H_{\mathrm{c}}$. The reduced static remanence curves, which are an indication of the distribution of the switching fields over the particles in the recording surface, of the $\gamma-\mathrm{Fe}_{2} \mathrm{O}_{3}$ and $\mathrm{Fe}$ tape coincide although there is a difference in signal strength of more than $10 \mathrm{~dB}$, figure 10 .

The advances in recording performance achieved in the past five years and the potential progress, can be seen from table III and are illustrated by figure 9 . At

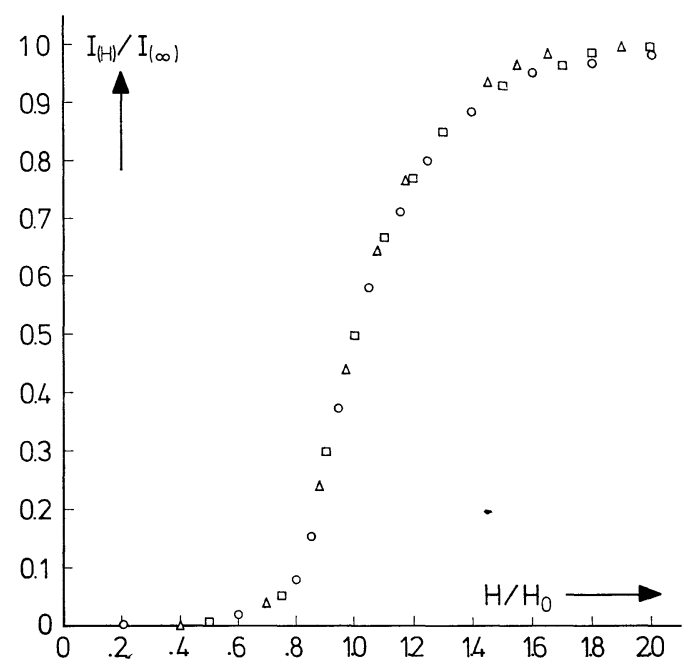

FIG. 10. - Reduced static remanence curves of $\gamma-\mathrm{Fe}_{2} \mathrm{O}_{3} \square$, $\mathrm{CrO}_{2} \triangle$ and Fe-metal $\bigcirc$ tapes. Vertical scale : Relative remanent magnetization $\left(I_{\mathrm{R}} / I_{\infty}\right)$. Horizontal scale : Relative field strength, $H$, with respect to the field at a remanence of half the maximum value, $H_{0}$.

a medium wavelength the $\gamma-\mathrm{Fe}_{2} \mathrm{O}_{3}$ gained $3-5 \mathrm{~dB}$ in signal to noise ratio, there is an additional contribution for short wavelengths of the, however, non compatible $\mathrm{CrO}_{2}$ of 3-4 dB while with iron powders a potential gain of another $6 \mathrm{~dB}$ may be reached.

For slow speed audio recording the iron tape could give a quality very close to that of grammophone records. Whether this will really be achieved on a technical scale depends on a number of factors of which the most important are :

- the mechanical performance of the recordertape system,

- the availability of appropriate write- and eraseheads.

The latter theme could be the subject of another discussion.

Acknowledgment. - The author gratefully acknowledges the discussions with Mrs. C. Jouwersma and D. L. A. Tjaden. 


\section{References}

[1] BATE, G., Alstad, J., I. E. E. E. Trans. on Magnetics MAG 5 (1969) 821.

[2] Bate, G., A. I. P. Proc. 17th Conf. magn. and magn. mat. (Chicago 1971) part I, p. 766.

[3] Smaller, P., Ann. N. Y. Acad. Sci. 189 (1972) 102.

[4] Judge, J. S., Ann. N. Y. Acad. Sci. 189 (1972) 117.

[5] MeE, C. D., The physics of magnetic recording (NorthHolland publ. Cy., A'dam) 1964.

[6] Mallinson, J. C., A. I. P. Proc. 17th Conf. magn. and magn. mat. (Chicago 1971), p. 743.

[7] Tuaden, D. L. A., Philips Techn. Rev. 25 (1964) 319.

[8] TJaden, D. L. A., I. E. E. E. Trans. on Magnetics MAG 5 (1969) 325.

[9] Curland, N., Speliotis, D. E., I. E. E. E. Trans. on Magnetics MAG 7 (1971) 538.

[10] Potter, R. I., Schmulian, R. J., I. E. E. E. Trans. on Magnetics MAG 7 (1971) 873.

[11] Daniel, E. D., J. Aud. Eng. Soc. 20 (1972) 92.

[12] DuInker, S., Tijdschrift Radio Genootschap 22 (1957) 29.

[13] TakeI, H., Chiba, Sh., J. Phys. Soc. Japan 21 (1966) 1255.

[14] van Oosterhout, G. W., Acta Crystallogr. 13 (1960) 932.

[15] Namikawa, T., Tochinara, Sh., I. E.E.E. Trans. on Magnetics MAG 9 (1973) 188.

[16] Eagle, D. F., Mallinson, J. C., J. Appl. Phys. 38 (1967) 995.

[17] Camras, M., U. S. Patent 2694656 (1954).

[18] Penniman, R. S., Zoph, N. M., U. S. Patent 1368748 (1921).

[19] Pfizer, German Pat. Appl. 2212435 (1972).

[20] LiMA-DE-FARIA, J., Z. Krist. 119 (1963) 203.

[21] Yada, Y., MiYamoto, S., I. E. E.E. Trans. on Magnetics MAG 9 (1973) 185.

[22] Gustard, B., Wright, M. R., I. E. E. E. Trans. on Magnetics MAG 8 (1972) 426.

[23] Speliotis, D. E., Morrison, J. R., Bate, G., Proc. Int. Conf. on Magnetism, Nottingham 1964.

[24] Ampex, U. S. Patent 3748270 (1971).

[25] 3 M-Company, U. S. Patent 3573980 (1971).

[26] AMPeX, German Pat. Appl. 2100390 (1971).

[27] Eastman-Kodak, French Pat. Appl. 2129841 (1972).

[28] Toda-Kogyo, U. S. Patent 3720618 (1973).

[29] SonY, Dutch Pat. Appl. 7301614 (1973).

[30] Krones, F., Technik der Magnetspeicher (Springer-Verlag, Berlin) 1960.

[31] Naumann, K. E., Daniel, E. D., J. Aud. Eng. Soc. 19 (1971) 822.
[32] Eastman Kodak, French Pat. Appl. 2129841 (1972). AMPEX, U. S. Patent 3748270 (1973).

TodA Kogyo, U. S. Patent 3720618 (1973).

SonY, Dutch Pat. Appl. 7301614 (1973).

A. N. V. A. R., Dutch Pat. Appl. 7305050 (1973).

BAyer, German Pat. Appl. 2221264 (1973).

Mastertape, German Pat. Appl. 2106125 (1971).

[33] Cloud, W. H., Darnell, F. J., Bull. Soc. Chim. France 4 (1965) 1164.

[34] Rodbell, D. S., J. Phys. Soc. Japan 21 (1966) 2430.

[35] Darnell, F. J., J. Appl. Phys. 32 (1961) 1269.

[36] Dismukes, J. P. et al., Ind. Eng. Chem. Prod. Res. Div. 10 (1971) 319.

[37] Roy, R., Bull. Soc. Chim. France (1965) 1065.

[38] Montecatini, German Pat. Appl. 2130547 (1971).

[39] Du Pont, Dutch Pat. Appl. 6803177 (1968).

[40] Du Pont, Dutch Pat. Appl. 6803331 (1968).

[41] NipPon Chemical, German Pat. Appl. 2030327 (1971).

[42] BAYER, German Pat. Appl. 1955896 (1971).

[43] Guillaud, Ch., Michel, A., Bénard, J., Fallot, M., C. R. Hebd. Séan. Acad. Sci. 219 (1944) 58.

[44] Svoboda, F. J. P., Arthur, A., Cox, W. L., Ingraham, J. N., Oppegard, A. L., Sadler, M. S., J. Appl. Phys. Suppl. 32374.

[45] Du PonT, French Patent 1154191 (1958).

[46] Jordan, L. K., Kerr, R. J., Dickens, J. E., J. Aud. Eng. Soc. 20 (1972) 2.

[47] Luborsky, F. E., Morelock, C. R., J. Appl. Phys. 35 (1964) 2055.

[48] Luborsky, F. E., J. Appl. Phys. 32 (1961) 171S.

[49] Oppegard, A. L., Darnell, F. J., Miller, H. C., J. Appl. Phys. 32 (1961) 184S.

[50] Iwasaki, S., Nagai, K., Proc. Conf. Sign Rec. on mov. media. Akadémiai Kiadó, Budapest 1964, p. 211.

[51] Stegherr, A., Werkstoffe u. Korrosion 23 (1972) 180.

[52] Graham Magnetics, German Pat. Appl. 2214445 (1972).

[53] 3M-CompanY, German Pat. Appls. 2326258 (1973); 2326261 (1973).

[54] Carman, E. H., Metallurgia 52 (1955) 165.

[55] Giessen, A. A. v. d., Klomp, C. J., I. E. E. E. Trans. on Magnetics MAG 5 (1969) 317.

[56] Ampex, German Pat. Appl. 2118103 (1971).

[57] KaWASAKI, M., Higuchi, Sh., I. E. E. E. Trans. on Magnetics MAG 8 (1972) 552.

[58] v. d. Giessen, A. A., I. E. E. E. Trans. on Magnetics MAG 9 (1973) 192 